\title{
OBITUARY
}

\section{PROFESSOR P. M. SHEPPARD, F.R.S.}

Philip Macdonald Sheppard (27 July 1921 to 17 Oct. 1976) was the first professor of genetics at Liverpool University from 1963 to 1976, having become reader in the new sub-department in 1959 and guided it to full departmental status. He will be remembered, however, much more for his superb experimental work in population and human genetics, his acute mind, his brillant teaching, and the amazing and wholly genuine stoicism with which he made things easier for his friends when he was suffering from acute leucaemia. He enjoyed helping others with any sort of problem in genetics, he never allowed anyone to get away with the slightest woolliness in thought or expression, and his loss will be felt deeply in genetical circles for many years to come. Obituaries have appeared in Nature and elsewhere, and an official biography has been prepared for the Royal Society by Sir Cyril Clarke, F.R.S. The purpose of this account is to summarise his contributions to genetics.

When he returned from a P.O.W. camp in Germany at the end of the war, he entered Worcester College, Oxford, and read Honours Zoology, in which he achieved only an upper second, having concentrated on his beloved genetics. He had already considerable experience in breeding lepidoptera, and made contact with Professor E. B. Ford, who with Sir Ronald Fisher was working on a now famous polymorphic population of the moth Panaxia dominula (the Scarlet Tiger) in a fen at Cothill, near Oxford. Philip was invited to join the work, and went on with Ford as his supervisor to his D.Phil. (1951), with the aid of a Christopher Welch Scholarship. He came into my room one day and complained somewhat emphatically about " this wretched moth "- - only one brood a year, only one variety to work on (the heterozygote medionigra for which this population was polymorphic, the homozygote bimacula being too rare to give useful data), weeks of mothhunting in wind, rain, nettles and brambles, months of boredom on the calculator (this was before electrical ones), and nothing then until the next season. "Surely there's something more polymorphic we could work with?" By good fortune I had a paper bag (this was before plastic) of Cepaea shells on my table and I showed them to him. That did it-I have never had anyone appreciate a situation so rapidly, interrogate me on what was then known so effectively, and make such exciting proposals for work. A few days later I was at an adult education college in Wiltshire and collected two very small samples; I was struck with the preponderance of morphs that resembled the general background on which I'd collected them. So I put them out in front of him and said, "Tell me where I got these". Immediately he said, "If I can tell that by looking at them, they must resemble the background-you're thinking of visual selection-all right, that's from a beech wood; and this, I don't know, some sort of wood anyway, but not beech". He was right both times, and the rapidity and the accuracy of his response was highly characteristic.

In his work on Panaxia dominula, by mark-release-recapture and continuing the long-term survey on the original population, by introducing the gene 
to other natural populations, by study of artificial populations, and by experiment on mating-choice of the different morphs, he greatly extended the work of Fisher and Ford, confirmed that the frequency of medionigra was controlled almost entirely by selection, and showed that apart from its effects on colour-pattern, it affected mating habits, fertility, and survival in the larval stage. It decreased to very low frequency at Cothill but after about 1957 began to increase again until 1969. M. H. Williamson showed that its non-random mating could maintain it in a polymorphism, and Philip considered that it was probably more robust than the rapidly-breeding normal form in bad years.

Similarly with the snail Cepaea nemoralis, our initial surveys in the Oxford district showed a relationship between the proportions of the colour morphs and the background that could best be explained as due to visual selection by predators; Philip went on to demonstrate visual selection by thrushes on carefully marked snails, with different marks according to the exact areas in which they were placed; he therefore knew exactly from what part of the general population each individual found on a thrush-stone had been brought-an essential piece of information never obtained up till then, and sometimes neglected since.

Both in this work on snails, and in the continuation of Fisher and Ford's studies on the Scarlet Tiger, he began (as I did) with a firm conviction that it was highly unlikely that such marked variation could be neutral. He was too good a field naturalist not to know that the interrelations between individuals and their environment may be exceedingly complex, and to dismiss enigmatic variation after a little half-hearted work, as neutral, or non-selective, was useless. At the same time, he very early made himself master of the relevant statistical techniques for testing whether real regularities in the data had been found or not.

Before his move to Liverpool he had made contact with Cyril Clarke who, besides being an outstanding member of the medical community there, was an accomplished lepidopterist, had published on the hand-pairing of species of swallow-tail butterflies (Papilio) and had begun hybridising species successfully. They realised what magnificent material these butterflies were for investigating both genetic differences between species and the genetic mechanism of mimetic polymorphism in the females, a subject obscure from lack of information and too many theories. In a series of papers they were able to show that each mimetic morph is not the result of a single mutant as Goldschmidt thought, but of a complex of genes, with a switch-gene changing the phenotype from one mimetic form to another. Crossing of widely separated populations brought about a disorganisation of the genotype, with the production of poorly mimetic forms, some of which occurred very rarely in the wild, or not so rarely where the models were scanty or absent and the selective value of the mimicry was reduced. Their results supported the theories of Fisher and Ford that a new mimetic form originated from a mutation happening to give a vague resemblance to a hitherto unused model, and selection then accumulated modifiers to improve the resemblance. They worked especially on Papilio dardanus, polytes and memnon but on various other species, too, and gave a singularly complete genetic account of the polymorphic mimicry, the occurrence of non-mimetic races, the production of rare semi- or non-mimetic forms, and the build-up of supergenes to control the wing-patterns. 
Philip went on with John Turner and others to look at a more puzzling situation, the apparent occurrence of polymorphism in highly distasteful butterflies of the genus Heliconius in South America. While these species could well join locally in Müllerian mimetic rings, clubbing together, so to speak, to use the same warning to predators of their nastiness, each population in a species should be monomorphic. They were able to show that most of the apparent polymorphism was due to populations mimicking different species in the refuge areas to which they were confined during the climatic changes of the Pleistocene, and then spreading out and hybridising with nearby populations of the same species but resembling a different mutually mimetic group.

In Cepaea also, he initiated a breeding-programme (necessarily a longterm effort) which showed massive supergenes, dominance and epistatic hierarchies, and an abundant " universal recessive " morph, a set-up characteristic of many visible polymorphisms. With Cyril Clarke he began work on invisible polymorphisms; they were particularly interested in the Rhesus blood-groups since these seemed to show a supergenic organisation. Furthermore, there were apparent interactions between Rhesus and duodenal ulcer. Both with these and ABO, Philip Sheppard worked out methods of investigation which were statistically valid; as a result they disproved some of the reported associations between blood-groups and disease, confirmed or established others, and went on, with their studies of interactions between the $\mathrm{ABO}$ groups and Rhesus, to make a highly practical suggestion for mitigating Rhesus haemolytic disease of the new-born. Philip Sheppard became deeply interested in tylosis and cancer of the oesophagus, the specificity of antibodies, and anencephaly and spina bifida, and it is mournful to think of how much he might have contributed to medical genetics.

He normally had many different lines of research running at once, and while working on polymorphic mimicry, populations of the Scarlet Tiger, and blood-groups, he, with Clarke, J. A. Bishop and others, made important extensions of the work by Ford and Kettlewell on industrial melanism in the Peppered Moth Biston betularia, working out the genetics of the intermediate form insularia, and monitoring with excitement the decrease in frequency of the melanics with the spread of no-smoke zones. All his lines of work interacted with each other, and in all of them natural selection was the evolutionary force in which he was most interested.

A. J. CAIN

Department of Zoology, University of Liverpool 